\title{
Imagining the Future of Digital Archives and Collections
}

\section{Editorial}

\section{Vivian van Saaze, Claartje Rasterhoff and Karen Archey}

Introduction

The web of digitized collections and archives in the field of arts and culture is rapidly expanding. Almost all arts and heritage institutions have digital collections, which are increasingly shared online, via institutions' own websites and through collaborative resources such as Wikidata. Many memory institutions embrace the digitization of their archives and collections, not only as a means to preserve and safeguard data but also as an opportunity to attract new audiences and increase engagement with their collections, programs, and research. When, in 2019, the EU member states signed a declaration of cooperation on advancing digitization of cultural heritage, they emphasized that "digital transformation can play an essential role in enabling cultural experiences, knowledge creation, preservation, and use and re-use of cultural heritage across borders. Digitized cultural objects, moreover, unlock the potential for broader societal, cohesive and economic benefits of sectors such as tourism, education and creative sectors."[1] This declaration points at what Jenny Kidd describes as the "promise of the digital" for public heritage; a democratization of the notion of heritage and disruption of existing categories and ideas such as ownership and authorship. 
Yet not only does the digital imperative in arts and memory institutions evoke promises for impact and innovation, it also brings about new questions and challenges for practitioners. [2] In a recent survey on digitization and copyright by the Network of European Museum Organisations (NEMO), responding museums note persistent challenges, such as financial difficulties, legal uncertainties, and the need for adequate skill development.[3] Moreover, in the same report, researchers suggest that a mechanism is missing to track the digitization process and online accessibility in many museums, and notice a lack of communication between stakeholders involved in cultural heritage digitization processes. The digital transformations observed in memory and arts institutions challenge existing modes of knowledge production and dissemination, and require new competencies and new forms of collaboration.

This issue of Stedelijk Studies investigates how we imagine ongoing digital transformations, and how this affects museological, artistic, and academic practices. It identifies and scrutinizes the forceful visions and promises of digitization, such as better connectivity, inclusivity, and easy and unlimited access to cultural data. These promises often kick-start and drive large-scale and costly digitization projects, as well as the development of digital infrastructures. While such promises are designed to support collaboration and increase accessibility and re-use of collections, they also shape and transform practices and expectations. How do collective visions of the future of archives and collections transform current knowledge production and exchange among museum workers, archivists, academics, technicians, artists, and other creative practitioners? And how do dominant scientific and technological developments in the digitization of memory institutions such as libraries, museums, and archives interact with other dimensions of social life?

\section{Imaginaries}

In this issue we employ the notion of "imaginaries" to shed light on the promises, expectations, narratives, and beliefs that inform and shape the digitization of archives and collections in the field of arts and culture. The notion of imaginaries_or, more specifically, sociotechnical imaginaries, as developed by Science and Technology (S\&T) scholarship-is usually applied in the context of broader technological developments such as nanotechnology. 4] The sociotechnical imaginary concept was developed by Sheila Jasanoff and Sang-Hyun Kim in 2009. Aiming to remedy the undertheorization of the relationship of science and technology to political power, they employed the term "sociotechnical imaginary" to describe how visions of scientific and technological progress carry with them implicit ideas about public purposes, collective futures, and the common good.[5] In 2015, Jasanoff redefined imaginaries as "collectively held, institutionally stabilized, and publicly performed visions of desirable futures, animated by shared understandings of 
forms of social life and social order attainable through, and supportive of, advances in science and technology."[6] Promises and expectations-as part of imaginaries-thus co-shape the transformations and impact the outcome of those transformations. Sociotechnical imaginaries draw attention to how visions of developments in science and technology tend to come with broader expectations of the attainable future of societies-often with an emphasis on improvements and benefits. Such imaginaries are collectively produced in often implicit ways, in government policy, but also at the level of expert (academic) domains, or in organizations and firms, where imagined futures can justify investments and policy choices. S\&T researchers therefore often analyze policy documentation or interviews, as well as specific institutional arrangements, such as funding schemes, and material practices in order to study how imaginaries are constituted and change over time.[7]

In the field of media studies, researchers have also applied the broader concept of imaginaries to understand the emergence of specific technological innovations and analyze how collective social visions and fantasies are informed and mediated by technology. Here, the internet is of specific interest.[8] In his book The Internet Imaginaire (2007), sociologist Patrice Flichy examines two main domains of the technical imaginaire in his study of the collective vision that shaped the emergence of the internet: the utopias and subsequent ideologies associated with the development of technical devices, and the depictions of an imaginary digital society.[9] Recent sociohistorical analyses include media scholar Paolo Bory's From the Internet Imaginary to Network Ideologies, in which he analyses dominant narratives that contributed to the construction of the "Internet myth" at the expense of other visions of the networked society. The web, like many media, is of course not a single, stable object.[10] From text analyses, for instance, two contrasting media imaginaries of the Web emerge. The first, Web 2.0, shortly put, describes the shift of the World Wide Web from a collection of texts to one of user engagement, interactivity, and community networks. The second, the Semantic Web, describes a vision for developing a common framework for sharing and reusing data across applications. Both are "deployed as a means of prioritizing frames of function and frames of use to shape the Web's socio-technical development."[11]

Accounts of the rise and construction of dominant technologies can serve as a framework to understand how technologies can also take root and acquire meaning in cultural domains such as arts, heritage, and digital humanities. On a broader, societal level, such frameworks can overlap with studies on datafication, which critically examine how dominant technologies transform the ordering of information and knowledge and its impacts on social life. In his recent book Engines of Order: A Mechanology of Algorithmic Techniques, new media scholar Bernhard Rieder examines how these information ordering techniques are embedded in technical infrastructures and economic logics, and how they "act as engines of order that actively modulate relationships between users and circulating units 
of various kind operate on existing patterns and fault lines in diversified yet unequal societies."[12]

Within the field of arts and heritage, using imaginaries as an analytical lens allows us to identify-and critically engage with-the promises and expectations that are part and parcel of the digitization and datafication of archives and collections. This issue of Stedelijk Studies reflects on these promises and expectations, with the aim of encouraging practitioners and academic researchers to revisit past and current digitization efforts. Together these contributions offer a rich and diverse insight in the efforts to develop, maintain, and reflect on a range of digitization projects of cultural archives and collections. The issue includes contributions from research practitioners and artists, combining these reflexive, insider perspectives with more historical and theory-driven analyses. Moreover, it addresses the complexities of interdisciplinary collaboration between different forms of expertise, as well as cross-institutional collaboration between museums, universities, and archives.

All contributions, some more explicitly than others, touch on particular promises, such as democratization and inclusivity connected to the digitization of institutional collections. While these promises in and of themselves warrant more research, the approaches reveal three particularly valuable avenues for further research: (art) historical, institutional, and artistic. In the following sections, we discuss the individual contributions along these three lines. By mobilizing the concept of sociotechnical imaginaries and organizing the contributions according to the promises they address (and in most cases, challenge), the issue assumes a practiceoriented perspective and aims to open up a conversation about the role of promises, expectations, and deeply rooted imaginaries in shaping digitization projects and practices.

\section{Democratization, inclusivity, and access}

The notion of imaginaries connects the past, present, and future of digitization practices. Awareness of the different promises and sociotechnical imaginaries at play in the field of digital heritage can help us reflect on how future visions of society shape current research and innovation, as well as our assessment of past efforts. It helps us to draw attention to how the technologies and practices (such as crowdsourcing) in digital heritage and humanities are interwoven with ideas about future societal change and benefits for the collective good. Take, for example, linked data, a set of design principles for sharing machine-readable interlinked data. While the associated techniques are themselves not entirely new, Linked Open Data (LOD) - that is, linked data that is freely open and re-publishable-is now particularly interesting to heritage institutions, possibly because it aligns well with visions about open access, inclusivity, and participation and thus appeals to morality.[13] Slowly but surely, heritage and cultural institutions are adopting linked open data as a way to organize and disseminate their collections, archives, and research, which would allow unlimited aggregation of 
materials from disparate geographical locations.[14] It promises a transition from specialized and siloed information in archives and museums to a web of cultural data. Yet the operationalization of linked open data comes with many questions and concerns, ranging from Web standards and domain-specific ontologies, loss of contextual information, presentation of provenance, and user interfaces, to legal and ethical considerations related to copyright and privacy.

Projects involving digital archives and collections are often also perceived as challenging traditional forms of knowledge production and consumption, and by extension, as questioning our cultural canons.[15] Through co-creation and participatory designs, such projects promise a less hierarchical form of knowledge production in which practitioners, academics, and, increasingly, citizens or niche experts are considered equal contributors to knowledge production.[16] The development of more inclusive and diverse digital "pipelines" that include crowdsourcing and folksonomies, however, also warrants practical, moral, and epistemological concerns over biases, authority, and accuracy, and issues of multiple interpretations and narratives.

Hande Sever's contribution to this issue discusses the Getty Research Portal as a case study of a digital repository that aims to be a global resource for the history of art of all cultures. The article demonstrates how the development of techniques is bound up with ideas on what would constitute a good social future (inclusive, diverse, open, etc.), but also how such institutional ambitions are restricted by past decisions. Visions for the functioning of the portal shape how we appreciate our current efforts and practices. Drawing on personal experience as a software developer working on the project, and informed by current research on biases and ethics within digital humanities, Sever disentangles the institutional and technical choices and arrangements that underpin the strong Western biases in the content of the portal.

Here, also, Lucy Bayley's work is relevant. Her article begins with an introduction to Richard Hamilton's Diab DS-101 Computer (1985-1989), in the collection of Tate, and the artist's 1995 proposal to create a networked artwork by connecting the machine to Tate's first-ever website, or to similar machines in other museums. The envisioned digital infrastructure functions as a springboard for Bayley to consider how, between the mid-1990s and 2013, Tate's digital strategy has been shaped and reshaped by sociotechnical narratives of access and inclusion. Demonstrating the persistence of institutional blockages, Bayley explores how ideals for the future shape current practices and priorities.

While Bayley and Sever discuss large-scale, institutionalized digitization projects, the conversation between Stedelijk Studies Co-Editor in Chief Sjoukje van der Meulen and artists and researchers Bo Zheng and Lu Pan focuses on self-initiated, experimental, visual archives created by scholars, artists, and activists in Asia. By drawing on examples such as the established Asia Art Archive (AAA) as well as the smaller-scale seachina.net, Bo and Lu challenge the "universal promise of democratization" and emphasize 
the value of online and physical archives around art and artists' initiatives as teaching and learning tools; as public platforms and places for social communication and community-building. The conversation also touches upon pertinent challenges of inequalities in access to digital resources and the (technical) incompatibility of archives, hindering collaboration.

Gabrielle Giannachi's contribution discusses The Floating Museum (1974-1978), a temporary museum comprising a set of commissioned artworks by over 300 artists, curated by artist Lynn Hershman Leeson. Many of these works were locative, participatory, and ephemeral interventions in public space. In its current state, The Floating Museum is conceived as "an assemblage of both documents and records" and preserved at the Department of Special Collections at Stanford University Libraries. The case is used to draw attention to the necessity for archiving practices to not only digitize existing documents about artworks but also to generate new, contextual documentations that capture the experiences of participants (both artists and past and present publics). Giannachi makes a plea for digitization projects to "not merely treat past performance and new media documents as historical products, but rather as complex live assemblages tracing the evolving life of a work."

\section{Innovation, sustainability, and collaboration}

The combination of contributions to this issue also demonstrates how the notion of imaginaries allows us to go beyond analyses of individual archives and collections. By comparing and contrasting several digitization projects, the issue aims to arrive at a richer understanding of the collective imaginaries that guide and inform the development of techniques and applications in digital archives and collections. Analyzing the narratives and ideals behind innovation projects (such as co-creation and co-production of public services) in relation to what is funded and by whom, might also help tease out power relations in digital heritage.

Some scholars have argued that future imaginaries feature as core elements in innovation processes and their governance.[17] Here, studying the political economy of our fields might be of particular interest, by focusing on ownership patterns, organizational structures, and business operations, as well as the way these practices are shaped by laws, regulations, and other policies-and local contexts more generally. The institutional arrangements of digital infrastructures impact research practices (and by extension, preservation and collection and archiving practices).

"Examining the mundane workings of infrastructure therefore becomes central to understanding practice."[18]

To gain deeper insight in the institutional arrangements of digital infrastructures, we invited a number of key voices (scholars, practitioners, artists) in the Netherlands' digital heritage field to participate in a round table discussion on a specific opportunity and challenge unique to digital 
infrastructures created for the archiving and exchange of cultural data: sustainability. While digital infrastructure initiatives often receive project funding in the start-up phase, because of the promise of innovation and progress, their long-term technical, organizational, and financial prospects are rife with challenges. Together the participants explored how the notion of imaginaries might be made productive in assessing the processes and outcomes of digitization projects of memory institutions, in light of presumed promises of innovation and increased functionality. They also questioned what is meant by success and failure in digitization projects and reflected on what type of digitization projects are desirable or required in the future, and in particular on the (potential) role of artists in imagining the future of digital archives and collections.

Christina Kamposiori's contribution highlights another prominent feature of the institutional arrangements in the field of digital humanities: the importance of collaboration across practitioners and researchers. In her analysis of the benefits of, but also practical obstacles in multi-stakeholder collaborations, she emphasizes the critical role that the staff and collections of libraries, archives, and museums can play in knowledge production in digital humanities. By actively studying users' (in this case, researchers') needs and practices and involving them in early stages of the creation of digital collections and other types of resources, such as data sets and tools, she gives pointers on how cultural institutions can make the most of collaborations.

Collaborative practice can, in turn, enable memory institutions to meet pressing challenges, such as a lack of resources and infrastructure, but also to engage with their audiences in new and innovative ways.

Collaboration within art institutions is a central theme in the contribution by Martina Haidvogel and Layna White on complex media installations. Their article is an experiencebased case study of SFMOMA's adoption of the MediaWiki platform as a documentation tool. Because contemporary artworks are so complex and heterogeneous, they argue, museums need to shift their practice and use of Collection Management Systems for documentation, and "lean into the 'uncomfortably open-ended' territory that comes with acquiring, loaning, exhibiting, and caring for these works of art." The article makes a clear case for institutions to invest in fostering interdisciplinary and cross-departmental collaboration, creating appropriate physical spaces and developing adequate forms of documentation, such as MediaWiki.

Philip Messner shifts our focus from collections to archives of art institutions. From a practitioner's perspective, he points out that despite their democratic ideals, archives of public institutions are often not easily (digitally) accessible. To help remedy this, he calls for collective action, shared infrastructures, and more attention for the subject of practical archival care, especially in Europe. In this respect, it is also critical for art institutions and their archives that digital preservation is recognized as a trade that needs to be structurally funded and institutionally embedded. To illustrate this point, he discusses specific practices in North America, where archivists of galleries and art museums are, in his 
view, much more integrated in the archival professional discourse than their European counterparts.

Among the promises of digital archives is the safeguarding of cultural treasures from natural aging and the threat of devastating calamities. The apocalyptic fire that destroyed the National Museum of Brazil in Rio de Janeiro is one such calamity, which resulted in the near-total loss of an entire country's museological collecting over the course of 200 years. Zooming out from the practitioner's perspective of the preceding two essays to the broader lens of national heritage, Ana Helena Arévalo's essay reflects on the fire, its transformation of the National Museum's collection, and the role of its humble digital archive, which comprises approximately $1 \%$ of its collection as digital surrogates. What the state of Brazil now faces, posits Arévalo, is the monumental task of conceptualizing and executing the National Museum's reconstruction. "Such reorganization will occur at all levels of governance, in the comprehensive reconsideration of its systematic, taxonomical, curatorial, museological, and archival orders. This merely reinforces the position (and potential) of archives and archival practices in terms of the preservation, conservation, and mediation of histories, narratives, and memories."

\section{Novelty, experiment, and glitch}

Finally, the concept of imaginaries elucidates the performativity, normativity, and discursiveness of promises and expectations. As social theorists have argued, imaginaries are neither innocent nor neutral; they shape our perceptions and elicit our actions, even if we may not realize it.[19] "They are "collective, durable, capable of being performed; yet they are also temporally situated and culturally particular."[20] Defining the present in terms of promises for the future affects how we assess the present, and leads to what S\&T scholar Harro van Lente has called "the promise-requirement cycle."[21] Thanks to the promise of unlimited access to data-fueled by common larger societal imaginaries around digitization, such as inclusivity and participation-we perceive the current situation as deficient and thus assess the present state of affairs as unfinished or unsuccessful. This deficiency is then solved by trying to realize the promise of unlimited access.

While the promise-requirement cycle is strongly linked to notions of "innovation" and "novelty," typically understood as improvement, some contributions in this issue challenge this strong focus on equating digitization with progress, and how the digitization or digital humanities projects is promoted and evaluated. Can innovation by digitization also be seen as differentiation or actively searching for novelty in terms of experimentation, instead of progress and improvement? In his contribution to the round table discussion, media artist and database art pioneer Geert Mul argues for experiment and open-endedness; a perspective that is admittedly often lacking in state or institutional initiatives.

Sjoukje van der Meulen's article explores the history of socalled "database art" since the 1990s and the various ways in which artists and designers have contributed to the imagination of digital archives and databases. She argues that art that employs databases has "a pioneering role in opening up and expanding our ideas and approaches to 
archives and collections in the digital world." Van der Meulen identifies two main "genres": firstly, projects engaging with algorithms, creating "counter-stories" or "anarchives" and reflecting on "how data is structured, mapped, and visualized in digital archives and collections; and secondly, projects engaging with databases through the development of novel interfaces. Together the database art projects discussed in her article also demonstrate how such projects can raise insight and more general societal awareness about how databases work and function.

The research-based practice of artist Rosa Menkman sheds light on a catalyst driving the utopian promises of sociotechnical imaginaries: digital degradation. Her video contribution It Takes More than the Past to Understand and Build the Archive (2020), commissioned especially for this issue of Stedelijk Studies, tells the story of her renowned work $A$ Vernacular of File Formats (2010). The work is an archive of a years-long research project into file formats, which are encoding systems that organize data according to a certain syntax. A Vernacular of File Formats brings together intentionally digitally broken or "glitched" images. It centers on one source image - a portrait of the artist herself-compressed with various file formats introduced with a similar error, revealing the unique aesthetic of how they organize data. Menkman's contribution sheds light on the decade since the work's creation. From its 2016 coacquisition by the Museum of the Image, Breda, and the Stedelijk Museum Amsterdam to today, her video describes the historical, social, and chance contexts that originally produced this work, and how our relationship to our own images and data have evolved since-to deleterious effect.

Menkman's video is marked by the subjectivity of her storytelling. Her personal reflections on the archive contrasts the false but persistent promise of archival objectivity and neutrality. To end at the beginning, Menkman's video starts out with a consideration of our current moment, defined by COVID-19. "I think it's very timely to talk about archives and time capsules right now," she states. "During the COVID pandemic it seems like time has found a new form of elasticity. I find that I spend my time just pondering the past or thinking about the future. I don't make a lot of new experiences or work, but rather resign myself to maintenance and archival work."

\section{Acknowledgements}

The guest editors would like to thank the authors, peerreviewers, and conversation partners for their thoughtful contributions to this issue, as well as Harro van Lente for his valuable insights and comments on an earlier version of the editorial. A special thanks also to Co-Editor in Chief Sjoukje van der Meulen for her engaged supervision and valuable insights on this issue, as well as Managing Editors Gwen Parry and Esmee Schoutens for their graceful guidance. 


\section{Biographies}

Vivian van Saaze is Associate Professor at the Faculty of Arts and Social Sciences of Maastricht University where she heads the Master's programme Arts and Heritage and the research centre MACCH (Maastricht Centre for Arts and Culture, Conservation and Heritage). She specialises in the study of museum practices by integrating theories and methods from anthropology, museum studies, and science and technology studies. Research interests include institutional challenges and opportunities arising from digitalisation and inherently unstable artworks such as installation art, digital art, and performance art.

Claartje Rasterhoff works at Boekman Foundation: Institute for arts, culture and related policy as a project leader of the new Culture Monitor. In addition, she recently started as Assistant Professor in Cultural Policy and Management at Maastricht University. Trained as a historian, her research takes place at the intersection of cultural policy, urban history, and the digital humanities, with a specific interest in digital heritage. Recent projects include the history of cultural industries (CREATE), culture \& commoning (Contemporary Commoning), and societal applications of digital heritage (Time Machine).

Karen Archey is a curator, editor, and art critic and Curator of Contemporary Art at the Stedelijk Museum Amsterdam. At the Stedelijk, she organizes contemporary art exhibitions and performances, and heads the museum's research initiative on the acquisition, conservation and display of timebased media. Formerly based in Berlin and New York, Archey organized with Robin Peckham the exhibition Art Post-Internet (2014) at Ullens Center for Contemporary Art, Beijing. In 2015 she was awarded a Creative Capital | Warhol Foundation Arts Writers Grant.

- [1] "EU Member States sign up to cooperate on digitizing cultural heritage" (April 9,

2019), https://ec.europa.eu/digital-singlemarket/en/news/eu-member-states-sign-cooperatedigitising-cultural-heritage, accessed September 10, 2020. See also the inDICes project on measuring the impact of digital culture: "The Cultural Heritage Sector is a key enabler of the advancement of the Cultural and Creative Industries in Europe. Not only does it provide access to vast amounts of reusable cultural content, it can be seen as a R\&D lab of the cultural and creative ecosystem through which it contributes both to the economic advancement and to society at large," https://indices-culture.eu, accessed September 10, 2020.

- [2] Jenny Kidd, "Public heritage and the promise of the digital," in The Oxford Handbook of Public Heritage Theory and Practice, eds. Angela M. Labrador and Neil Asher Silberman (Oxford: Oxford University Press, 2019), doi: 10.1093/oxfordhb/9780190676315.013.9. 
- [3] According to the NEMO report on digitization and copyright, published on July 15,2020 , more than $80 \%$ of the responding museums claimed increased visibility as the main objective for digitizing their collections, closely followed by $75 \%$ of museums which named increased access and educational use. See

- https://www.ne-mo.org/news/article/nemo/nemo-reporton-digitisation-and-copyright-challenges-of-makingmuseum-collections-accessible-online.html, accessed September 10, 2020.

- 44] As an academic field, Science \& Technology Studies focuses on the complex interplay between society, politics, and culture, and scientific and technological developments.

- 5] Sheila Jasanoff and Sang-Hyun Kim, "Containing the atom: Sociotechnical imaginaries and nuclear power in the United States and South Korea," Minerva 47, no. 2 (2009): 119-146; Sheila Jasanoff, "Future Imperfect: Science, Technology, and the Imaginations of Modernity," in Dreamscapes of Modernity:

Sociotechnical Imaginaries and the Fabrication of Power, eds. Sheila Jasanoff and Sang-Hyun Kim (Chicago: Chicago University Press, 2015), 133, https://dx.doi.org/10.7208/chicago/9780226276663. 001.0001.

- [6] Jasanoff, "Future Imperfect," 4.

- [8] Paolo Bory, The Internet Myth: From the Internet Imaginary to Network Ideologies (London: University of Westminster Press, 2020), doi: https://doi.org/10.16997/book48.d.

- [9] Patrice Flichy, The Internet Imaginaire (Cambridge, MA: MIT Press, 2007); Patrice Flichy, "The Construction of New Digital Media", New Media \& Society 1, no. 1 (1999): 33-39, doi: 10.1177/1461444899001001006.

- [10] Frédérik Lesage and Louis Rinfret, "Shifting media imaginaries of the Web," First Monday 20, no. 10 (2015), doi: http://dx.doi.org/10.5210/fm.v20i10.5519.

- [11] lbid.

- [12] Bernhard Rieder, Engines of Order: A Mechanology of Algorithmic Techniques (Amsterdam: Amsterdam University Press, 2020), 45, doi: 10.5117/9789462986190.

- [13] Marta Poblet, Pompeu Casanovas, and Víctor Rodríguez-Doncel, Linked Democracy: Foundations, Tools, and Applications, SpringerBriefs in Law (New York: Springer International Publishing, 2019), doi: https://doi.org/10.1007/978-3-030-13363-4.

- [14] Ed Jones and Michele Seikel, eds., Linked Data for Cultural Heritage (Chicago: American Library Association, 2016); Seth van Hooland and Ruben Verborgh, Linked Data for Libraries, Archives and Museums (London: Facet Publishing, 2014).

- [15] Maria Vincenza Ciasullo, Orlando Troisi, and Silvia Cosimato, "How Digital Platforms Can Trigger Cultural Value Co-Creation? - A Proposed Model," Journal of Service Science and Management 11 (2018): 161-181, doi: 10.4236/jssm.2018.112013.

- [16] Mia Ridge, ed., Crowdsourcing our Cultural Heritage (Farnham: Ashgate, 2014). 
- [17] Kornelia Konrad and Knud Böhle, "Socio-technical futures and the governance of innovation processes An introduction to the special issue," Futures 109 (2019): 101-107, https://doi.org/10.1016/i.futures.2019.03.003.

- [18] Agiatis Bernadou, Erik Champion, Costis Dallas, and Lorna M. Hughes, eds., Cultural Heritage Infrastructures in Digital Humanities, Digital Research in the Arts and Humanities (London/New York: Routledge, 2018), 12.

- [19] See George E. Marcus, ed., Technoscientific Imaginaries: Conversations, Profiles, and

Memoirs (Chicago: University of Chicago Press, 1995).

- [20] Jasanoff and Kim, "Future Imperfect," 19.

- [21] Harro van Lente, "Navigating foresight in a sea of expectations: Lessons from the sociology of expectations," Technology Analysis \& Strategic Management 24, no. 8 (2012): 769-782; Harro van Lente, Promising Technology: The Dynamics of Expectations in Technological Developments (Delft: Eburon, 1993). 